\title{
Awareness and Use of Complementary and Alternative Medicine in Korean Lung Cancer Patients
}

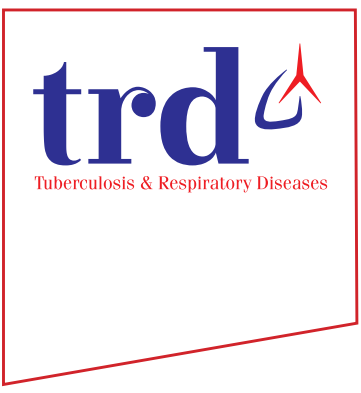

Joon Young Choi, M.D. ${ }^{1}{ }^{(\mathbb{0},}$, Wonjun Ji, M.D., Ph.D. ${ }^{2}$, Chang-Min Choi, M.D., Ph.D. ${ }^{2,3}$, Chaeuk Chung, M.D., Ph.D. ${ }^{4}$, Jae Myoung Noh, M.D., Ph.D. ${ }^{5}$, Cheol-Kyu Park, M.D., Ph.D. ${ }^{6,7}$, In-Jae Oh, M.D., Ph.D. ${ }^{6,7}$, Hong In Yoon, M.D., Ph.D. ${ }^{8}$, Hyeong Ryul Kim, M.D., Ph.D. ${ }^{9}$, Ho Young Kim, M.D., Ph.D. ${ }^{10}$, Chang Dong Yeo, M.D., Ph.D. ${ }^{11} \mathbb{C}^{\mathbb{D}}$, Seung Hun Jang, M.D., Ph.D. ${ }^{12}$, , on behalf of the Public Relation Committee of the Korean Association for Lung Cancer

*Author affiliations appear at the end of this article.

Background: Complementary and alternative medicine (CAM) has been used frequently, and its use continues to increase in lung cancer patients, despite insufficient scientific of its efficacy. To investigate this situation, we analyzed the current awareness and use of CAM in Korean lung-cancer patients.

Methods: This prospective survey-based study was performed at seven medical centers in South Korea between August and October 2019. The survey assessed general patient characteristics and the awareness and use of CAM. We analyzed differences in the clinical parameters of patients aware and not aware of CAM and of CAM non-users and users.

Results: Of the 434 patients included in this study, $68.8 \%$ responded that they were aware of CAM and $30.9 \%$ said they had experienced it. In univariate analysis, the patients aware of CAM were younger with poor performance status, had advanced-stage lung cancer, received more systemic therapy, and received concurrent chemoradiation therapy (CCRT). By multiple logistic regression, younger age, poor performance status, advanced stage, and prior CCRT were identified as independent risk factors for CAM awareness. There were no significant differences in the general characteristics and cancer-associated clinical parameters of CAM non-users and users.

Conclusion: Specific clinical parameters were associated with patients' awareness of CAM, although there were no significantly different characteristics between CAM users and non-users.

Keywords: Complementary Therapies; Lung Neoplasms; Awareness; Cross-sectional Studies; Prospective Studies

Address for correspondence: Seung Hun Jang, M.D., Ph.D.

Division of Pulmonary, Allergy and Critical Care Medicine, Department of Internal Medicine, Hallym University Sacred Heart Hospital, Hallym University College of Medicine, 22 Gwanpyeong-ro 170 beon-gil, Dongan-gu, Anyang 14068, Republic of Korea

Phone: 82-31-380-3718, Fax: 82-31-380-3973, E-mail: chestor@hallym.or.kr

Address for correspondence: Chang Dong Yeo, M.D., Ph.D.

Division of Pulmonary, Critical Care and Sleep Medicine, Department of Internal Medicine, Eunpyeong St. Mary's Hospital, College of Medicine, The Catholic University of Korea, 1021 Tongil-ro, Eunpyeong-gu, Seoul 03312, Republic of Korea

Phone: 82-2-2030-4310, Fax: 82-2-2030-2617, E-mail: brainyeo@catholic.ac.kr

Received: Sep. 3, 2020, Revised: Nov. 5, 2020, Accepted: Dec. 8, 2020, Published online: Dec. 8, 2020

(a) It is identical to the Creative Commons Attribution Non-Commercial License (http://creativecommons.org/licenses/by-nc/4.0/). 


\section{Introduction}

Lung cancer is the most common cancer and responsible for the highest cancer-related mortality worldwide ${ }^{1-4}$. Although the age-adjusted incidence and cancer-related mortality of lung cancer have decreased in previous decades, the treatment of lung cancer is still a challenging issue that devastates both clinicians and patients ${ }^{5}$. Regarding these circumstances, some patients choose to use therapies that are not scientifically proven or based on insufficient evidence. These therapies are used either as supplementary/additive measures (complementary medicine) or alternative measures (alternative medicine) to conventional cancer treatment. Such therapies are usually referred to as complementary and alternative medicine $(\mathrm{CAM})^{6,7}$.

The motivations for using CAM are diverse. Patients expect to gain a better general condition, improve their immune system, relieve cancer symptoms or treatment side effects, and prolong survival ${ }^{6,8}$. However, the results of previous studies on the efficacy and safety of CAM vary from beneficial to harmful $^{6,79-13}$. Thus, a thorough understanding of these results by both patients and clinicians is needed before starting treatment with CAM. Nonetheless, previous studies have shown that many patients choose to use CAM regardless of the scientific basis, relying more on media or non-specialists than physicians, which may be biased by secondary gain, personal subjective experience, or unproven information ${ }^{8}$. As CAM is now frequently used worldwide in cancer patients and its use continues to increase, its effects on cancer patients should not be overlooked ${ }^{14-16}$. Therefore, it may be important to analyze the current status of CAM awareness and the use of CAM to guide patients in choosing their treatment.

In this study, we conducted a multicenter survey-based study to investigate the current status of CAM awareness and use in lung cancer patients, and analyzed the factors associated with the awareness and use of CAM. Furthermore, we investigated the adverse events, costs, and perspectives toward CAM in CAM users.

\section{Materials and Methods}

\section{Study design and data collection}

This study was a prospective survey-based study performed in seven medical centers in South Korea. The patients enrolled in this study had pathologically confirmed lung cancer and replied to questionnaires in a survey on CAM use between August 2019 and October 2019 (Supplementary Material). The survey consisted of two sections. The first section was composed of 13 questions on patient demographics and information associated with the patient's disease (i.e., lung cancer staging and treatment), which was attained by the attending physicians. The second section was composed of 15 questionnaires regarding the awareness and use of CAM, which was self-reported by the patient in the outpatient clinic.

\section{General characteristics and awareness of CAM use}

The patients enrolled in this study were provided with a paper survey on personal CAM awareness and use. The questionnaires consisted of general characteristics such as age, sex, Eastern Cooperative Oncology Group (ECOG) performance status, smoking history (ever or never smoker), and economic status (low vs. medium vs. high). We also gathered information associated with the patient's disease, including lung cancer staging (TNM staging in non-small cell lung cancer [NSCLC], or limited/extended staging in small cell lung cancer [SCLC]), past treatment history (e.g., surgery, radiation therapy, systemic therapy or concurrent chemoradiation therapy [CCRT]), candidates for targeted therapy (epidermal growth factor receptor $[E G F R] /$ anaplastic lymphoma kinase $[A L K]$ mutation), line of systemic therapy, and treatment durations. We analyzed the differences in these factors in patients aware and not aware of CAM and in CAM users and non-users. The general patient characteristics were also compared with a previous unbiased Korean nationwide study that extracted data from the Korean Association of Lung Cancer Registry (KALCR) in 2014 to investigate whether the enrolled patients represented the general cancer population of Korea ${ }^{17}$.

\section{Awareness of CAM}

The survey included questions on CAM awareness. The questionnaires of the awareness of CAM were answered in one of the three: "never heard", "heard only a little" or "known thoroughly". The patients were questioned about their familiarity with procedures or techniques of CAM, such as oncothermia, high-dose vitamin C, mistletoe, selenium, Gerson therapy, bio-photon, thymosin alpha 1 , nebulized oriental medicine, acupuncture or moxibustion, oriental medicine, mushrooms, ginseng, or reiki treatments. Furthermore, the questionnaire included questions on the route through which CAM information was obtained, the patient's expectation of efficacy, and whether CAM was based on scientific evidence.

\section{Current status of CAM use}

In patients who were aware of CAM, they were asked whether they had received any CAM procedure or medicine. The patients who selected 'yes' to that question were asked what specific types of CAM they experienced, when they received CAM (before, during, or after conventional therapy), the duration of CAM use, and their economic status. Also, the questionnaires asked about adverse events and the cost of using CAM. 


\section{Statistical analysis}

All statistical analyses were performed with R software (version 3.5.2, R Development Core Team, Vienna, Austria). The quantitative variables are presented as mean \pm standard deviations, and the categorical variables are shown as numbers and percentages. The quantitative variables were assessed between the two groups with a student's t test and the categorical variables were compared with the chi-square test or Fisher exact test. A p-value of less than 0.05 was considered statistically significant.

We performed multiple logistic regression to reveal the relationship between CAM awareness and potential associated factors. First, we performed univariate logistic regression

Table 1. Patient characteristics and comparison with Korean nationwide lung-cancer-registry study (KALC-R)

\begin{tabular}{|lcc|}
\hline \multicolumn{1}{|c}{ Clinical parameter } & $\begin{array}{c}\text { This study } \\
(\mathbf{n}=\mathbf{4 3 4})\end{array}$ & $\begin{array}{c}\text { KALC-R study } \\
(\mathbf{n}=\mathbf{2 , 6 2 1})\end{array}$ \\
\hline Male sex & $308(71.0)$ & $1,876(71.6)$ \\
\hline Age, yr & $66(60-74)$ & $70(61-76)$ \\
\hline Performance status (ECOG) & & \\
$0-1$ & $382(91.4)$ & $1,756(93.8)$ \\
\hline $2-4$ & $36(8.6)$ & $117(6.2)$ \\
\hline Smoking history & & \\
\hline Ever smoker & $288(66.4)$ & $1,641(63.6)$ \\
\hline Never smoker & $146(33.6)$ & $980(36.4)$ \\
\hline Stage & & \\
\hline NSCLC & $384(88.5)$ & $2,265(86.4)$ \\
\hline I-II & $127(33.0)$ & $824(36.9)$ \\
\hline III-IV & $257(66.9)$ & $1,410(63.1)$ \\
\hline SCLC & $50(11.5)$ & $356(13.6)$ \\
\hline Limited & $27(52.9)$ & $128(36.6)$ \\
\hline Extended & $24(47.1)$ & $222(63.4)$ \\
\hline Treatments* & & \\
\hline Surgery & $167(40.8)$ & $861(33.0)$ \\
\hline Systemic therapy & $225(54.9)$ & $870(33.3)$ \\
\hline Cytotoxic & $157(38.4)$ & - \\
\hline Immunotherapy & $59(14.4)$ & - \\
\hline Targeted therapy & $71(17.3)$ & - \\
\hline Chemoradiation & $117(28.5)$ & $151(5.8)$ \\
\hline Radiation therapy & $79(19.3)$ & $205(7.8)$ \\
\hline
\end{tabular}

Values are presented as number (\%), mean $\pm S D$, or median (IQR). *Patients may have received more than two treatment modalities. KALC-R: Korean Association of Lung Cancer Registry; ECOG: Eastern Cooperative Oncology Group; NSCLC: non-small cell lung cancer; SCLC: small-cell lung cancer; SD: standard deviation; IQR: interquartile range.
Table 2. Factors affecting CAM awareness of lung-cancer patients

\begin{tabular}{|c|c|c|c|}
\hline Clinical parameter & $\begin{array}{c}\text { Aware (-) } \\
(\mathrm{n}=135 \\
\mathbf{3 1 . 2 \% )}\end{array}$ & $\begin{array}{c}\text { Aware }(+) \\
(\mathbf{n}=\mathbf{2 9 8} \\
\mathbf{6 8 . 8 \%})\end{array}$ & p-value \\
\hline Sex & & & 0.41 \\
\hline Male & $97(71.9)$ & $210(70.5)$ & \\
\hline Female & $38(28.1)$ & 88 (29.5) & \\
\hline \multicolumn{4}{|l|}{ Age, yr } \\
\hline$\geq 65$ & $86(63.7)$ & $155(52.0)$ & 0.03 \\
\hline$<65$ & $49(36.3)$ & $143(48.0)$ & \\
\hline Performance status & & & $<0.01$ \\
\hline ECOG 0 & $68(53.5)$ & $111(38.3)$ & \\
\hline ECOG 1-4 & $59(46.5)$ & $179(61.7)$ & \\
\hline Pathology & & & 0.98 \\
\hline NSCLC & $120(88.9)$ & $263(88.3)$ & \\
\hline SCLC & $15(11.1)$ & $35(11.7)$ & \\
\hline \multicolumn{4}{|l|}{ Stage } \\
\hline NSCLC I & $44(36.7)$ & $41(15.6)$ & $<0.01$ \\
\hline NSCLC II-IV & $76(63.3)$ & $222(84.4)$ & \\
\hline SCLC limited & $7(46.7)$ & $20(55.6)$ & 0.79 \\
\hline SCLC extended & $8(53.3)$ & $16(44.4)$ & \\
\hline \multicolumn{4}{|l|}{ Treatments* } \\
\hline Surgery & $58(46.0)$ & $108(38.3)$ & 0.17 \\
\hline Systemic therapy & $59(46.8)$ & $165(58.3)$ & 0.04 \\
\hline Chemoradiation & $20(15.9)$ & $97(34.3)$ & $<0.01$ \\
\hline Radiation therapy & $18(14.3)$ & $60(21.3)$ & 0.13 \\
\hline EGFR/ALK (+) & $34(27.4)$ & $75(26.0)$ & 0.87 \\
\hline Line of systemic therapy & & & 0.46 \\
\hline 1 & $37(44.0)$ & $73(38.4)$ & \\
\hline$\geq 2$ & $47(56.0)$ & $117(61.6)$ & \\
\hline Treatment duration, yr & & & 0.72 \\
\hline$\geq 1$ & $69(51.9)$ & $159(54.3)$ & \\
\hline$<1$ & $64(48.1)$ & $134(45.7)$ & \\
\hline Economic status & & & $>0.99$ \\
\hline Low & $2(28.6)$ & $26(26.3)$ & \\
\hline Medium-to-high & $5(71.4)$ & $73(73.7)$ & \\
\hline
\end{tabular}

Values are presented as number (\%).

*Patients may have received more than two treatment modalities. CAM: Complementary and alternative medicine; ECOG: Eastern Cooperative Oncology Group; NSCLC: non-small cell lung cancer; SCLC: small cell lung cancer; EGFR: epidermal-growth-factor receptor; ALK: anaplastic lymphoma kinase. 
A
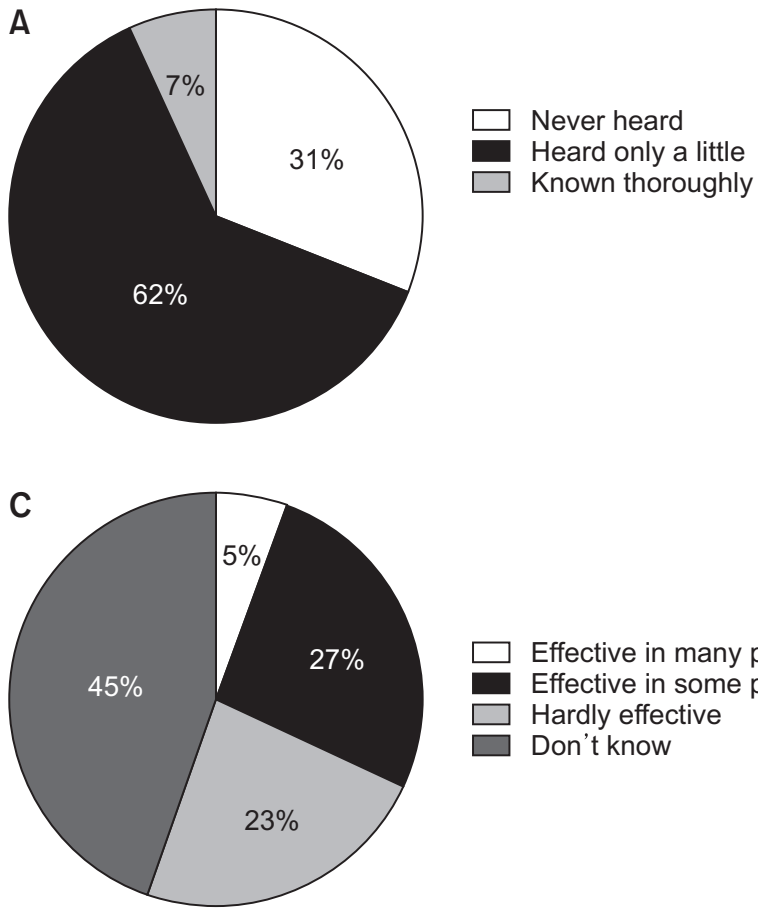

B

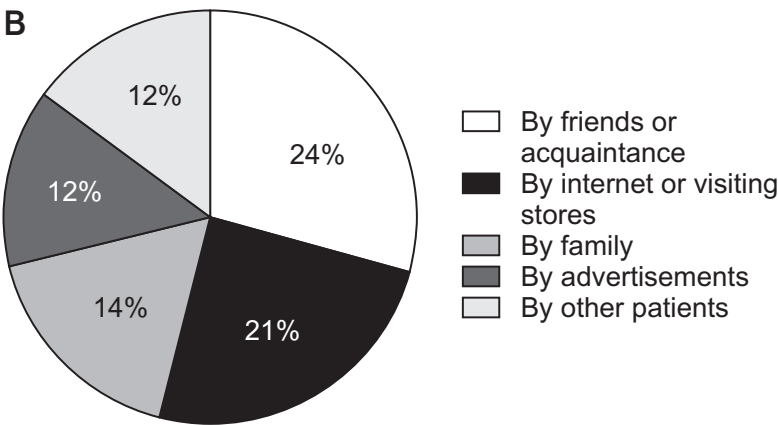

D

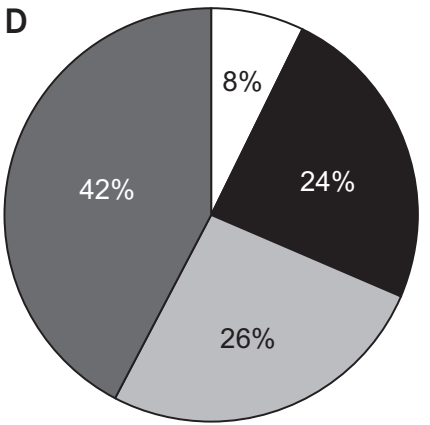

Proven sufficiently

Proven by some evidence

Not proven to be scientific

Don't know

Figure 1. Patient awareness of complementary and alternative medicine (CAM): (A) proportion of patients aware of CAM, (B) route of acquisition of information on CAM, (C) patient awareness that CAM is effective, and (D) patient awareness of CAM as scientifically proven.

Table 3. Multiple logistic regression of factors associated with CAM awareness

\begin{tabular}{|c|c|c|c|c|}
\hline \multirow{2}{*}{ Variable } & \multicolumn{2}{|c|}{ Univariate analysis } & \multicolumn{2}{|c|}{ Multivariate analysis } \\
\hline & OR (95\% CI) & p-value & OR $(95 \% \mathrm{CI})$ & p-value \\
\hline \multicolumn{5}{|l|}{ Age, yr } \\
\hline$<65$ & $1.62(1.07-2.46)$ & 0.02 & $2.09(1.24-3.53)$ & $<0.01$ \\
\hline$\geq 65$ & Reference & & Reference & \\
\hline \multicolumn{5}{|c|}{ Performance status } \\
\hline ECOG $1-4$ & $1.86(1.22-2.83)$ & $<0.01$ & $2.03(1.20-3.44)$ & $<0.01$ \\
\hline ECOG 0 & Reference & & Reference & \\
\hline \multicolumn{5}{|l|}{ NSCLC } \\
\hline Stage II-IV & $3.13(1.90-5.16)$ & $<0.01$ & $1.96(1.01-3.79)$ & 0.046 \\
\hline Stage I & Reference & & Reference & \\
\hline \multicolumn{5}{|l|}{ Systemic therapy } \\
\hline$(+)$ & $1.59(1.04-2.42)$ & 0.03 & $1.22(0.69-2.17)$ & 0.49 \\
\hline$(-)$ & Reference & & Reference & \\
\hline \multicolumn{5}{|l|}{ Chemoradiation } \\
\hline$(+)$ & $2.76(1.62-4.73)$ & $<0.01$ & $2.07(1.05-4.06)$ & 0.04 \\
\hline$(-)$ & Reference & & Reference & \\
\hline
\end{tabular}

Hosmer Lemeshow goodness of fit, $\mathrm{p}=0.61$.

CAM: complementary and alternative medicine; OR: odds ratio; CI: confidence interval; ECOG: Eastern Cooperative Oncology Group; NSCLC: non-small cell lung cancer. 
to select the candidate risk factors for CAM awareness. The variables included age ( $\geq 65$ years vs. $<65$ years), sex, ECOG performance status (0 vs. 1-4), NSCLC staging (I vs. II-IV), and past treatment history (surgery, CCRT, systemic therapy, radiation therapy). Variables with a p-value of less than 0.05 in univariate analysis were selected for multiple logistic regression analysis. The adjusted odds ratio (OR) of each variable for CAM awareness was calculated.

\section{Ethics approval and consent to participate}

Ethical approval was obtained from the Ethics Committee of Hallym University Sacred Hospital, and the IRB number was HALLYM201909001001-HE001. The requirement for informed consent was waived by the Ethics Committee of Hallym University Sacred Hospital.

\section{Results}

\section{General characteristics}

A total of 434 patients were enrolled in this study. The flow chart of patients' enrollment is shown at Supplementary Figure S1. The general characteristics and comparison to the characteristics of a cancer population in a previous study (KALC-R) are shown in Table $1^{17}$. In this study, $71.0 \%$ of the patients were male and $91.4 \%$ of the patients had an ECOG scale score of 0 to 1 , which was similar to the KALC-R study. The mean patient age in this study was $65.8 \pm 9.9$ years, which was slightly younger than the patients in the KALC-R study. The proportion of ever smokers was similar between the two studies $(66.4 \%$ in the current study vs. $63.6 \%$ in the KALCR study). In the analysis of cancer stages, the proportion of NSCLC patients was similar between the two studies. However, our study showed more limited-stage SCLC patients than the KALC-R study ( $52.9 \%$ vs. $36.6 \%$, respectively). Our study population received more treatment by all modalities compared with the KALC-R study (surgery, $40.8 \%$ vs. 33.0\%; systemic therapy, $54.9 \%$ vs $33.3 \%$; CCRT, $28.5 \%$ vs. $5.8 \%$; radiotherapy, $19.3 \%$ vs. $7.8 \%$, respectively).

\section{Awareness of CAM}

We analyzed the differences in the characteristics and clinical parameters between patients aware of CAM and those not aware of CAM (Table 2). A total of $68.8 \%$ of patients were aware of CAM. Those aware of CAM were younger patients with poorer performance status. Among the NSCLC patients, patients aware of CAM had less stage I disease (15.6\% vs. $36.7 \%$, respectively, $\mathrm{p}<0.01$ ), but there was no significant difference in the cancer stage of the SCLC patients. Patients aware of CAM received more systemic therapy (58.3\% vs. $46.8 \%$,
Table 4. Factors that affected CAM use by lung-cancer patients

\begin{tabular}{|c|c|c|c|}
\hline Clinical parameter & $\begin{array}{c}\text { Use (-) } \\
(n=201, \\
69.1 \%)\end{array}$ & $\begin{array}{l}\text { Use }(+) \\
(n=90, \\
30.9 \%)\end{array}$ & p-value \\
\hline Sex & & & 0.47 \\
\hline Male & $144(71.6)$ & $60(66.7)$ & \\
\hline Female & $57(28.4)$ & $30(33.3)$ & \\
\hline Age, yr & & & 0.16 \\
\hline$\geq 65$ & $111(55.2)$ & $41(45.6)$ & \\
\hline$<65$ & $90(44.8)$ & $49(54.4)$ & \\
\hline Performance status & & & 0.47 \\
\hline ECOG 0 & $79(40.1)$ & $31(34.8)$ & \\
\hline ECOG $1-4$ & $118(59.9)$ & $58(65.2)$ & \\
\hline Pathology & & & 0.90 \\
\hline NSCLC & $176(87.6)$ & $80(88.9)$ & \\
\hline SCLC & $25(12.4)$ & $10(11.1)$ & \\
\hline \multicolumn{4}{|l|}{ Stage } \\
\hline NSCLC I & $28(15.9)$ & $11(13.8)$ & 0.80 \\
\hline NSCLC II-IV & $148(84.1)$ & $69(86.2)$ & \\
\hline SCLC limited & $16(64.0)$ & $4(36.4)$ & 0.24 \\
\hline SCLC extended & $9(36.0)$ & $7(63.6)$ & \\
\hline \multicolumn{4}{|l|}{ Treatments* } \\
\hline Surgery & $70(37.4)$ & $36(40.9)$ & 0.68 \\
\hline Systemic therapy & $113(60.1)$ & $48(54.5)$ & 0.46 \\
\hline Chemoradiation & $64(34.0)$ & $32(36.4)$ & 0.81 \\
\hline Radiation therapy & 39 (20.7) & $18(20.7)$ & $>0.99$ \\
\hline EGFR/ALK (+) & $51(26.2)$ & $22(25.6)$ & $>0.99$ \\
\hline Line of systemic therapy & & & 0.15 \\
\hline 1 & $57(42.2)$ & $15(29.4)$ & \\
\hline$\geq 2$ & $78(57.8)$ & $36(70.6)$ & \\
\hline Treatment duration, yr & & & 0.04 \\
\hline$\geq 1$ & $97(49.2)$ & $56(62.9)$ & \\
\hline$<1$ & $100(50.8)$ & $33(37.1)$ & \\
\hline Economic status & & & 0.12 \\
\hline Low & $6(50.0)$ & $20(23.8)$ & \\
\hline Medium-to-high & $6(50.0)$ & $64(76.2)$ & \\
\hline
\end{tabular}

Values are presented as number (\%).

*Patients may have received more than two treatment modalities. CAM: complementary and alternative medicine; ECOG: Eastern Cooperative Oncology Group; NSCLC: non-small cell lung cancer; SCLC: small cell lung cancer; EGFR: epidermal-growth-factor receptor; ALK: anaplastic lymphoma kinase. 
respectively, $\mathrm{p}=0.04$ ) and CCRT ( $34.3 \%$ vs. $15.9 \%$, respectively, $\mathrm{p}<0.01)$. However, there was no statistical difference in previous surgery or radiotherapy between the two groups. Furthermore, there was no statistical difference in sex, pathology type (NSCLC/SCLC), EGFR positivity or ALK mutations, the line of systemic therapy ( 1 vs. $\geq 2$ ), treatment duration ( $\geq 1$ year vs. $<1$ year), or economic status of the patients (low vs. medium-tohigh).

In this study, $6.9 \%$ of the patients responded that they were thoroughly aware of CAM and $31.1 \%$ of the patients answered that they never heard of it (Figure 1A). The most commonly known CAM treatments were mushrooms, oncothermia, high-dose vitamin C, and ginseng (Supplementary Figure S2). The most common route for obtaining information on CAM was through friends or acquaintances and by the internet or visiting stores (Figure 1B). Around one-third of the patients replied that CAM may be effective or was proven by scientific evidence, and the remainder regarded CAM as not effective, not proven scientifically, or did not know (Figure 1C, D).

Univariate analysis of CAM awareness with potential associated factors showed statistical significance with age $(\mathrm{p}=0.02)$, performance status $(\mathrm{p}<0.01)$, cancer staging in NSCLC $(\mathrm{p}<0.01)$, previous systemic therapy $(\mathrm{p}=0.03)$, and previous CCRT $(\mathrm{p}<0.01)$. Multiple logistic regression was performed with variables that showed significance in univariate analysis (Table 3). In this regression model, younger patients (OR, 2.09 ; $\mathrm{p}<0.01)$, poorer performance status $(\mathrm{OR}, 2.03 ; \mathrm{p}<0.01)$, advanced stage in NSCLC $(\mathrm{OR}, 1.96 ; \mathrm{p}=0.046)$, and previous CCRT (OR, 2.07; $\mathrm{p}=0.04)$ were associated with CAM awareness. The Hosmer Lemeshow goodness of fit had a calculated p-value of 0.61 .

\section{Usage of CAM}

We investigated the differences in the characteristics and clinical parameters between CAM users and non-users (Table 4). CAM users comprised $30.9 \%$ of our study population. CAM users had a tendency to be younger ( $54.4 \%$ vs. $44.8 \%$, respectively, $\mathrm{p}=0.16$ ), more likely to be female ( $33.3 \%$ vs. $28.4 \%$, respectively, $\mathrm{p}=0.47$ ), and in advanced stages in the NSCLC patients ( $86.2 \%$ vs. $84.1 \%$, respectively, $\mathrm{p}=0.80$ ), but the findings did not meet statistical significance. Also, there were no statistical differences in performance status, pathology, treatments, or economic status between the two groups. The only statistically significant factor was treatment duration of more than 1 year, which was more common in the CAM user group compared to the non-user group ( $62.9 \%$ vs. $49.2 \%$, respective$\mathrm{ly}, \mathrm{p}=0.04)$. However, no significantly different factors between the CAM users and non-users were found in multivariate analysis. The most frequently used CAM was mushrooms, oncothermia, ginseng, and high-dose vitamin C (Supplementary Figure S3) and most of the CAM users received CAM during conventional treatment (Figure 2A). The duration of CAM treatment was not significantly different (Figure 2B), and $74.0 \%$ of the patients were in the medium-to-high economic group (Figure 2C). A total of $24.2 \%$ of the patients experienced adverse events from CAM, mostly pruritus or rash, fatigue, and insomnia (Supplementary Figure S4). Almost half of the patients paid less than 1,000 USD and $21.1 \%$ of the patients paid over 5,000 USD for CAM (Supplementary Figure S5). Finally, only $18.9 \%$ of the CAM users were willing to recommend CAM to other patients and $45.3 \%$ of the patients were against recommending it (Supplementary Figure S6).

\section{Discussion}

In this study, we analyzed the awareness and usage of CAM in a multicenter survey-based lung cancer population. In the analysis of CAM awareness, $68.8 \%$ of the patients were
A

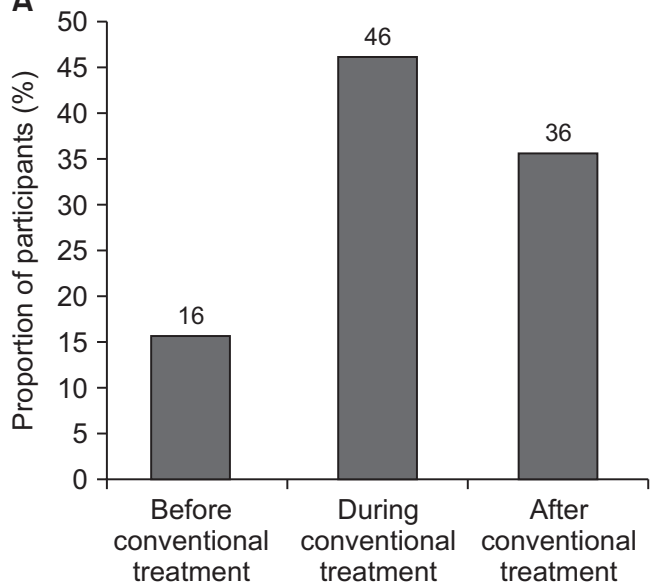

B

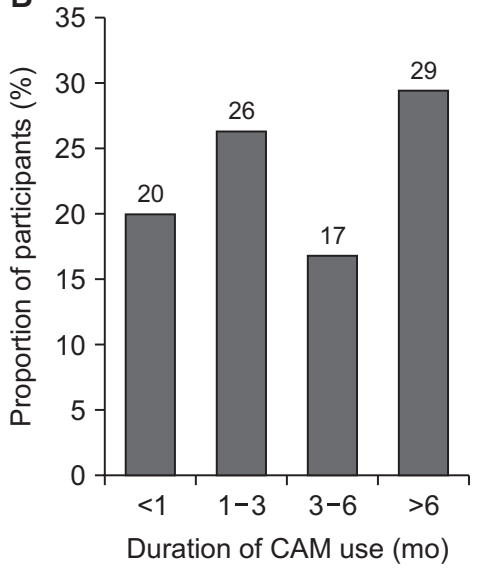

C

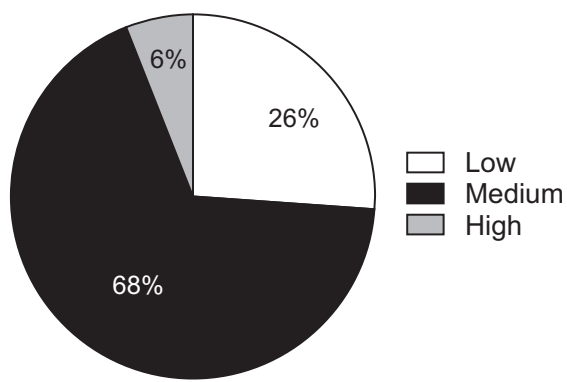

Figure 2. Timing (A) and duration (B) of complementary and alternative medicine (CAM) use, and economic status (C) of the CAM users. 
aware of CAM and more CAM users were younger patients with poor performance status, advanced stage in NSCLC patients, and those who received systemic therapy or CCRT. In multivariate analysis, young age, poor performance status, advanced stage in NSCLC patients, and previous CCRT were independent factors associated with CAM awareness. In contrast, there were no statistically significant variables that differed between the CAM users and non-users.

The proportion of cancer patients who experienced CAM was shown to be $30.9 \%$ in our study, and was reported to vary between $11 \%$ and $90 \%$ in previous studies ${ }^{18-20}$. Previous studies showed some distinct characteristics of CAM users compared to non-users. CAM users were usually younger; consisted of more female, educated, and white-collar patients; lived in highly urban areas; had advanced-stage cancer; were less physically active, and received psychological support ${ }^{8,14,21,22}$. Also, those who were interested in CAM or used CAM previously chose to use CAM more frequently ${ }^{8}$. Correspondingly, our study found that the CAM users were younger, more likely to be female, and at an advanced stage, but these findings did not reach statistical significance.

To our knowledge, no previous studies analyzed the factors associated with CAM awareness. However, it may be postulated that patients aware of CAM and CAM users share similar characteristics. Our study showed that patients aware of CAM were more likely to be younger, have poor performance status, and advanced stage in NSCLC patients, which corresponded to the characteristics of CAM users reported in the previous study mentioned above. Also, between treatment modalities, only CCRT was an independent risk factor for CAM awareness. Patients with unresectable stable III NSCLC or limited SCLC disease receiving CCRT may have higher potential for cure but higher treatment-associated toxicity than more advanced patients receiving palliative chemotherapy, which may result in a higher awareness of $\mathrm{CAM}^{23}$.

The World Health Organization (WHO) defined CAM as "a broad set of healthcare practices that are not part of that country's own tradition or conventional medicine and are not fully integrated into the dominant healthcare system ${ }^{24}$." Also, the organization mentioned that it might be used alternatively with traditional medicine. This definition implies that these interventions are not fully proven to be effective or safe, nor are they based on scientific evidence. Some experimental, retrospective studies or small prospective studies have shown the potential efficacy or safety of CAM, such as oncothermia $^{25,26}$, high-dose vitamin $\mathrm{C}^{25,27}$, mistletoe ${ }^{11,28,29}$, thymosin alpha $1^{30,31}$, or oriental medicine $e^{10,12,32-34}$. However, some studies have shown the harmful effects of CAM, such as treatment delay, treatment refusal, and increased mortality ${ }^{7,13,35}$. At the crossroads of choice, clinicians and patients should fully understand not only the potentially favorable outcomes but also the devastating consequences of CAM. However, our data and previous studies showed that the source of information about
CAM was mainly friends and the media ${ }^{8,14}$. These previous studies also reported the lack of doctors' roles in providing information about CAM. This situation may misguide patients to have meaningless hope, spend money recklessly, and, most seriously, refuse conventional treatment.

Most of the studies reported that the patients were usually satisfied ${ }^{36,37}$ with little or transient side effects ${ }^{14,38}$. However, our study showed that only $18.9 \%$ of the CAM users were satisfied and $24.2 \%$ experienced side effects from CAM. Considering the heterogeneity of each CAM intervention, satisfaction, and side effects should be analyzed by the type of CAM administered $^{15}$.

There were some limitations to this study. First, this study was a cross-sectional study based on a survey. As a result, this study design may include some bias, such as recall bias or selection bias. Second, as this study population was mainly enrolled in a secondary or tertiary hospital, it may not represent patients who were receiving conservative or palliative treatment in primary clinic or CAM clinics. Third, as described in Table 1, our patients consisted of more of limited-stage SCLC and were treated with all types of modalities compared to the previous population-based study ${ }^{17}$. We contend that the expanded concept of lung cancer screening may have resulted in increased numbers of lung cancer patients detected at earlier stages or with treatable disease ${ }^{39}$. Also, drastic improvements in treatments such as immunotherapy in the last decade may have increased the number of patients indicated for treatment ${ }^{40}$. Furthermore, as our survey was performed in outpatient clinics of secondary or tertiary hospitals, the patients enrolled in our study may have been more frequently followed-up and adhered to treatment.

Despite these limitations, there were some strengths to our study. First, to our knowledge, this was the first study to analyze factors associated with the awareness of CAM. We performed multivariate analysis to reveal the independent risk factors for patients aware of CAM. Also, we compared the variables that potentially differed between CAM users and non-users. Although there were no differences between the two groups, this was the first study that compared not only general characteristics such as age, sex, and economic status, but also the detailed variables associated with diagnosis and treatment, including pathology type, cancer staging, treatment modalities, EGFR/ALK mutation, and the line of systemic therapy. These factors were correspondingly analyzed between patients aware and not aware of CAM, which were not evaluated in previous studies.

In conclusion, we analyzed the differences in characteristics between patients aware of CAM and those not aware. By multivariate analysis, we concluded that patients with younger age, poor performance status, advanced stage, and those who received prior CCRT were more aware of CAM. They obtained information on CAM mostly from friends and acquaintances, and one-third of the patients responded that they believed 
CAM was effective or scientifically proven. There were no significantly different characteristics between CAM users and non-users.

\section{*Author Affiliations}

${ }^{1}$ Division of Pulmonary and Critical Care Medicine, Department of Internal Medicine, Incheon St. Mary's Hospital, College of Medicine, The Catholic University of Korea, Seoul, Departments of ${ }^{2}$ Pulmonology and Critical Care Medicine and ${ }^{3}$ Oncology, Asan Medical Center, University of Ulsan College of Medicine, Seoul, ${ }^{4}$ Division of Pulmonology, Department of Internal Medicine, Chungnam National University, Daejeon, ${ }^{5}$ Department of Radiation Oncology, Samsung Medical Center, Sungkyunkwan University School of Medicine, Seoul, ${ }^{6}$ Lung and Esophageal Cancer Clinic, Chonnam National University Hwasun Hospital, Hwasun, ${ }^{7}$ Department of Internal Medicine, Chonnam National University Medical School, Gwangju, ${ }^{8}$ Department of Radiation Oncology, Yonsei Cancer Center, Yonsei University College of Medicine, Seoul, ${ }^{9}$ Department of Thoracic and Cardiovascular Surgery, Asan Medical Center, University of Ulsan College of Medicine, Seoul, ${ }^{10}$ Division of Hematology-Oncology, Department of Internal Medicine, Hallym University Sacred Heart Hospital, Hallym University College of Medicine, Anyang, ${ }^{11}$ Division of Pulmonary, Critical Care and Sleep Medicine, Department of Internal Medicine, Eunpyeong St. Mary's Hospital, College of Medicine, The Catholic University of Korea, Seoul, ${ }^{12}$ Division of Pulmonary, Allergy and Critical Care Medicine, Department of Internal Medicine, Hallym University Sacred Heart Hospital, Hallym University College of Medicine, Anyang, Republic of Korea

\section{Authors' Contributions}

Conceptualization: Jang SH, Yeo CD. Methodology: Jang SH, Yeo CD, Choi CM, Chung C. Formal analysis: Choi JY, Yeo CD, Ji W. Data curation: Ji W, Choi CM, Chung C, Noh JM, Park CK, Oh IJ, Yoon HI, Kim HR, Kim HY, Yeo CD, Jang SH. Investigation: Ji W, Choi CM, Chung C, Noh JM, Park CK, Oh IJ, Yoon HI, Kim HR, Kim HY, Yeo CD, Jang SH. Writing - original draft preparation: Choi JY. Writing - review and editing: Choi JY, Jang SH, Yeo CD. Approval of final manuscript: all authors.

\section{Conflicts of Interest}

No potential conflict of interest relevant to this article was reported.

\section{Funding}

No funding to declare.

\section{Supplementary Material}

Supplementary material can be found in the journal homepage (http://www.e-trd.org).

Supplementary Figure S1. Flowchart of patents' enrollment.

Supplementary Figure S2. Patient awareness of specific complementary and alternative medicine.

Supplementary Figure S3. Patients' use of specific complementary and alternative medicine.

Supplementary Figure S4. Adverse events form complementary and alternative medicine: (A) yes/no and (B) type of adverse event.

Supplementary Figure S5. Cost of complementary and alternative medicine use.

Supplementary Figure S6. Willingness to recommend complementary and alternative medicine to other patients.

\section{References}

1. World Health Organization. WHO fact sheets [Internet]. Geneva: World Health Organization; 2018 [cited 2020 Apr 23]. Available from: https://www.who.int/news-room/fact-sheets/ detail/cancer

2. Hong S, Won YJ, Park YR, Jung KW, Kong HJ, Lee ES, et al. Cancer statistics in Korea: incidence, mortality, survival, and prevalence in 2017. Cancer Res Treat 2020;52:335-50.

3. Kim HC, Jung CY, Cho DG, Jeon JH, Lee JE, Ahn JS, et al. Clinical characteristics and prognostic factors of lung cancer in Korea: a pilot study of data from the Korean Nationwide Lung Cancer Registry. Tuberc Respir Dis 2019;82:118-25.

4. Park JY, Jang SH. Epidemiology of lung cancer in Korea: recent trends. Tuberc Respir Dis 2016;79:58-69.

5. Siegel RL, Miller KD, Jemal A. Cancer statistics, 2020. CA Cancer J Clin 2020;70:7-30.

6. Calcagni N, Gana K, Quintard B. A systematic review of complementary and alternative medicine in oncology: psychological and physical effects of manipulative and body-based practices. PLoS One 2019;14:e223564.

7. Johnson SB, Park HS, Gross CP, Yu JB. Use of alternative medicine for cancer and its impact on survival. J Natl Cancer Inst 2018;110:121-4.

8. Loquai C, Dechent D, Garzarolli M, Kaatz M, Kaehler KC, Kurschat P, et al. Use of complementary and alternative medicine: a multicenter cross-sectional study in 1089 melanoma patients. Eur J Cancer 2017;71:70-9.

9. Li CL, Hsia TC, Li CH, Chen KJ, Yang YH, Yang ST. Adjunctive traditional Chinese medicine improves survival in patients 
with advanced lung adenocarcinoma treated with first-line epidermal growth factor receptor (EGFR) tyrosine kinase inhibitors (TKIs): a nationwide, population-based cohort study. Integr Cancer Ther 2019;18:1534735419827079.

10. Shen HS, Wen SH. Effect of early use of Chinese herbal products on mortality rate in patients with lung cancer. J Ethnopharmacol 2018;211:1-8.

11. Schad F, Thronicke A, Steele ML, Merkle A, Matthes B, Grah $\mathrm{C}$, et al. Overall survival of stage IV non-small cell lung cancer patients treated with Viscum album L. in addition to chemotherapy, a real-world observational multicenter analysis. PLoS One 2018;13:e0203058.

12. Li TM, Yu YH, Tsai FJ, Cheng CF, Wu YC, Ho TJ, et al. Characteristics of Chinese herbal medicine usage and its effect on survival of lung cancer patients in Taiwan. J Ethnopharmacol 2018;213:92-100.

13. Johnson SB, Park HS, Gross CP, Yu JB. Complementary medicine, refusal of conventional cancer therapy, and survival among patients with curable cancers. JAMA Oncol 2018;4: 1375-81.

14. Molassiotis A, Fernandez-Ortega P, Pud D, Ozden G, Scott JA, Panteli V, et al. Use of complementary and alternative medicine in cancer patients: a European survey. Ann Oncol 2005; 16:655-63.

15. Horneber M, Bueschel G, Dennert G, Less D, Ritter E, Zwahlen M. How many cancer patients use complementary and alternative medicine: a systematic review and metaanalysis. Integr Cancer Ther 2012;11:187-203.

16. Barnes PM, Bloom B, Nahin RL. Complementary and alternative medicine use among adults and children: United States, 2007. Natl Health Stat Report 2008;(12):1-23.

17. Choi CM, Kim HC, Jung CY, Cho DG, Jeon JH, Lee JE, et al. Report of the Korean Association of Lung Cancer Registry (KALC-R), 2014. Cancer Res Treat 2019;51:1400-10.

18. Bozza C, Gerratana L, Basile D, Vitale MG, Bartoletti M, Agostinetto E, et al. Use and perception of complementary and alternative medicine among cancer patients: the CAMEO-PRO study: complementary and alternative medicine in oncology. J Cancer Res Clin Oncol 2018;144:2029-47.

19. Kim SH, Shin DW, Nam YS, Kim SY, Yang HK, Cho BL, et al. Expected and perceived efficacy of complementary and alternative medicine: a comparison views of patients with cancer and oncologists. Complement Ther Med 2016;28:29-36.

20. James PB, Bah AJ. Awareness, use, attitude and perceived need for Complementary and Alternative Medicine (CAM) education among undergraduate pharmacy students in Sierra Leone: a descriptive cross-sectional survey. BMC Complement Altern Med 2014;14:438.

21. Rossanaly Vasram R, Zysman M, Ribeiro Baptista B, Ederle C, Nguyen-Thi PL, Clement-Duchene C, et al. Complementary and alternative medicine use by lung cancer patients. Rev Pneumol Clin 2017;73:172-9.

22. Kuo YT, Chang TT, Muo CH, Wu MY, Sun MF, Yeh CC, et al.
Use of Complementary traditional Chinese medicines by adult cancer patients in Taiwan: a nationwide populationbased study. Integr Cancer Ther 2018;17:531-41.

23. Verma V, Simone CB 2nd, Werner-Wasik M. Acute and late toxicities of concurrent chemoradiotherapy for locally-advanced non-small cell lng cancer. Cancers (Basel) 2017;9:120.

24. Traditional, complementary and integrative medicine [Internet]. Geneva: World Health Organization; 2020 [cited 2020 Apr 28]. Available from: https://www.who.int/health-topics/traditionalcomplementary-and-integrative-medicine\#tab=tab_1.

25. Ou J, Zhu X, Lu Y, Zhao C, Zhang H, Wang X, et al. The safety and pharmacokinetics of high dose intravenous ascorbic acid synergy with modulated electrohyperthermia in Chinese patients with stage III-IV non-small cell lung cancer. Eur J Pharm Sci 2017;109:412-8.

26. Yeo SG. Definitive radiotherapy with concurrent oncothermia for stage IIIB non-small-cell lung cancer: a case report. Exp Ther Med 2015;10:769-72.

27. Klimant E, Wright H, Rubin D, Seely D, Markman M. Intravenous vitamin $\mathrm{C}$ in the supportive care of cancer patients: a review and rational approach. Curr Oncol 2018;25:139-48.

28. Yoon TJ, Yoo YC, Kang TB, Baek YJ, Huh CS, Song SK, et al. Prophylactic effect of Korean mistletoe (Viscum album coloratum) extract on tumor metastasis is mediated by enhancement of NK cell activity. Int J Immunopharmacol 1998;20: 163-72.

29. Bradley GW, Clover A. Apparent response of small cell lung cancer to an extract of mistletoe and homoeopathic treatment. Thorax 1989;44:1047-8.

30. Garaci E, Pica F, Matteucci C, Gaziano R, D’Agostini C, Miele MT, et al. Historical review on thymosin alphal in oncology: preclinical and clinical experiences. Expert Opin Biol Ther 2015;15 Suppl 1:S31-9.

31. Jiang J, Wang X, Tian J, Li L, Lin Q. Thymosin plus cisplatin with vinorelbine or gemcitabine for non-small cell lung cancer: a systematic review and meta-analysis of randomized controlled trials. Thorac Cancer 2011;2:213-20.

32. Bae K, Kim E, Kong JS, Kim J, Park SJ, Jun HJ, et al. Integrative cancer treatment may have a survival benefit in patients with lung cancer: a retrospective cohort study from an integrative cancer center in Korea. Medicine (Baltimore) 2019;98:e16048.

33. Yoo HS, Kim JM, Jo E, Cho CK, Lee SY, Kang HS, et al. Modified Panax ginseng extract regulates autophagy by AMPK signaling in A549 human lung cancer cells. Oncol Rep 2017;37: 3287-96.

34. Jiao L, Dong C, Liu J, Chen Z, Zhang L, Xu J, et al. Effects of Chinese medicine as adjunct medication for adjuvant chemotherapy treatments of non-small cell lung cancer patients. Sci Rep 2017;7:46524.

35. Angell M, Kassirer JP. Alternative medicine: the risks of untested and unregulated remedies. N Engl J Med 1998;339:83941.

36. Bahall M. Prevalence, patterns, and perceived value of com- 
plementary and alternative medicine among cancer patients: a cross-sectional, descriptive study. BMC Complement Altern Med 2017;17:345.

37. Sait KH, Anfinan NM, Eldeek B, Al-Ahmadi J, Al-Attas M, Sait $\mathrm{HK}$, et al. Perception of patients with cancer towards support management services and use of complementary alternative medicine: a single institution hospital-based study in Saudi Arabia. Asian Pac J Cancer Prev 2014;15:2547-54.

38. Wode K, Henriksson R, Sharp L, Stoltenberg A, Hok Nordberg
J. Cancer patients' use of complementary and alternative medicine in Sweden: a cross-sectional study. BMC Complement Altern Med 2019;19:62.

39. Triphuridet N, Henschke C. Landscape on CT screening for lung cancer in Asia. Lung Cancer (Auckl) 2019;10:107-24.

40. Cheng B, Xiong S, Li C, Liang H, Zhao Y, Li J, et al. An annual review of the remarkable advances in lung cancer clinical research in 2019. J Thorac Dis 2020;12:1056-69. 